\title{
Nas (in)definições de livro, leitor e leitura: uma multiplicidade de espaços e sentidos
}

\author{
Ilsa do Carmo Vieira Goulart ${ }^{1}$ \\ Dalva de Souza Lobo ${ }^{2}$
}

\section{Resumo}

Este trabalho considera que a palavra escrita ultrapassa a bidimensionalidade do papel ao ser interpretada, mutilada, reencenada e, por vezes, ironicamente esquecida no texto pelas múltiplas leituras que, não raro, são feitas por um mesmo leitor em diferentes momentos de sua história, ou em distintos estados de humor, age abrindo espaços, outros, de produção de sentidos. Deste modo, o artigo objetiva refletir sobre as representações estabelecidas na relação entre o leitor e a leitura, por intermédio do livro, tecidas a partir de uma rede discursiva que tramita essa tríade. A reflexão apresenta uma aproximação entre diferentes ideias, conceitos ou imagens que insinuam as (in)definições a partir de proposições a respeito do livro enquanto objeto mediador da ação leitora. Para tanto, com base no conceito de obra aberta de Eco, toma-se como fundamentação argumentativa a questão da materialidade do livro discutida por Chartier, o conceito de "rizoma" de Deleuze e Guattari e a reflexão de experiência descrita por Benjamin em diálogo com Larrosa.

Palavras-chave: livro; leitor; leitura; produção de sentidos

\section{In (in)definitions to book, reader and reading: a multiplicity of spaces and senses}

\begin{abstract}
This work considers that the written word exceeds the two-dimensional of the role to be played, mutilated, reenacted and sometimes ironically forgotten in the text, or for multiple readings that often are made by the same player at different times in its history, or even in different moods, others, in the production of meaning. The article aims to reflect on the established representations in the relationship between the reader and reading through the book, woven from a discursive network that clears this triad. To do so, from the concept of open work of Eco, as argumentative basis the question of materiality of the book placed by Chartier, the concept of "rhizome" of Deleuze and Guattari, and the reflection of experience described by Benjamin in dialogue with Larrosa.
\end{abstract}

Keywords: book; reader; reading; production of senses

\footnotetext{
${ }^{1}$ Departamento de Educação da Universidade Federal de Lavras. Lavras, MG - Br. E-mail: ilsa.goulart@ded.ufla.br

${ }^{2}$ Departamento de Educação da Universidade Federal de Lavras. Lavras, MG - Br. E-mail: dalva.lobo@ded.ufla.br
} 


\section{Introdução}

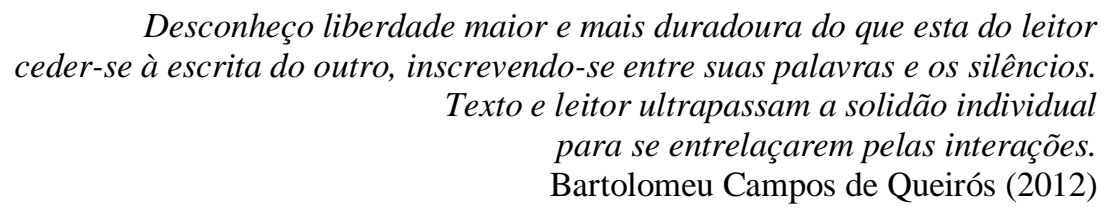

Cabem, neste ensaio, algumas inquietações que tramitam entre a relação leitor e a leitura permeada pelo objeto-livro, tendo em vista sua multiplicidade sígnica, sobretudo no que toca a ação leitora e ao livro, este último compreendido como espaço não fechado em si mesmo, mas que se move na abertura de ações interpretativas, inventivas e livres na produção de sentidos. O livro, mesmo em sua materialidade impressa, na demarcação e fixação das palavras escritas, libera a transitoriedade, a imparcialidade e a pluralidade dos sentidos produzidos; mesmo na aparente individualidade da ação leitora, permite-se ao leitor e texto "se entrelaçarem pelas interações", conforme a epígrafe; mesmo em cada leitura, em cada suporte que acolha as palavras escritas, a relação se modifica, abrem-se outros espaços de experiências, de criação e de diálogos.

Sabemos que a compreensão da leitura tem a ver com as diferentes visões de mundo nas quais estão incluídas elementos sociais, culturais e históricos que, devido às particularidades temporais e espaciais, instalam tensões seja entre o que se compreende ou não por livro, conforme aponta Ribeiro (2011), seja em busca de se entender os diferentes signos que constituem o sujeito e influenciam em sua leitura. O livro como um objeto de arte é produzido e organizado em seções provocativas de efeitos comunicativos, de modo que cada leitor possa recompreender, segundo nos descreve Eco (2010).

Nesta perspectiva, este exercício de escrita procura refletir a respeito das representações estabelecidas na relação entre leitor e leitura intermediada pelo livro a partir da rede discursiva em que orbita essa tríade, considerando as diferentes ideias, conceitos ou imagens que insinuam as (in)definições do que se entende por livro, tomando como base o conceito de obra aberta de Eco, balizada pela questão da materialidade de Chartier, pelo conceito de rizoma de Deleuze e Guattari e pela proposição de experiência descrita por Benjamin em diálogo com Larrosa, e com outros autores. 
(In)definir não é algo simples, por isso iniciamos pelos espaços de tensão criados pelos atos de leitura. Nesse sentido, traçamos uma discussão a respeito do livro como um lugar que excede a dimensão demarcada pela materialidade impressa. O livro como obra aberta, segundo Eco (1991), configura-se na exterioridade física, instituindo espaços abertos, imaginativos e passíveis de interpretações e sentidos múltiplos.

\section{O livro: espaços para além da materialidade concreta}

Rumores visionários da falência da indústria editorial em decorrência da anunciada extinção do livro aguçaram interesses e estudos historiográficos pelo tema. Estudos identificados com a História Cultural, como Chartier (1990, 1996, 1998, 1999, 2009) e Darnton (1990), apontaram para o fato de que a substituição de um suporte de texto por outro - rolos de papiros, códices, telas de computadores - poderia significar a perda, não só desse objeto, mas do mundo do qual ele, um dia, fez parte. Para outros a concepção de escrita nem sempre foi a mesma, como indicam os estudos de Gnerre (2009), segundo o qual, em diferentes momentos históricos ocorreram alterações significativas nas atitudes com relação à escrita, o que mudaria também o modo do seu processo de compreensão e apreensão, demarcadas por situações de uso funcional e intenso da escrita.

Na ausência de um único suporte para o texto, torna-se difícil aproximá-lo dos mesmos sentidos que os sujeitos um dia the atribuíram, das relações com ele construídas, das práticas e representações que circundaram este material de leitura. O fato de não haver um suporte exclusivo potencializa as representações decorrentes da leitura, tornada mais independente de um único código ou de uma única matriz de registro. A modificação do suporte exige do leitor uma inovação dos gestos, das práticas intelectuais. No percurso histórico do livro, do codex à tela, o passo significativo para esta inovação foi a passagem do rolo ao códex, visto que, foram criadas "[...] afirmadas ou impostas novas maneiras de ler que ainda não foi possível caracterizar totalmente, mas que, sem a menor dúvida, implicam práticas de leitura sem precedentes". (CAVALLO \& CHARTIER, 1998, p.32).

O suporte para mediação textual ganha terrenos investigativos frente à consideração de que a existência do texto só é possível acoplada a uma materialidade e de que não existe um texto fora do suporte que se dá à leitura. Segundo Chartier (1990, 1998), os autores não escrevem livros, mas textos que são transformados em objetos Revista Leitura V.2 no 56 - jul/dez 2016 - Número regular - Autor/a: Ilsa do Carmo Vieira Goulart; Dalva de Souza Lobo - p. 05-25. 
escritos, outrora manuscritos, gravados, depois impressos e, atualmente, disponibilizados em formato digital. Objetos que são manejados de diferentes formas por um leitor real, cuja maneiras de realizar a atividade de leitura não são as mesmas, variam, alteram-se em diferentes épocas, lugares e ambientes.

Assim, ao conceituar o livro apenas pela sua materialidade concreta pode-se criar uma ideia abreviada, reducionista frente a complexidade sígnica que o envolve. Dizer que os "livros são papeis pintados com tinta", como no poema de Fernando Pessoa (2002, p.90), poderia apresentar uma definição restrita à caracterização externa da obra impressa. Entretanto, o que se observa é que o objeto-livro envolve um ato criador, pois sua existência ou reconhecimento configura-se em relação ao seu leitor.

Descrever o livro impresso como um material que traz apenas marcas de tintas figura um conceito fechado na materialidade, torna-o objeto limítrofe e estático, pois sem a atribuição de significados a estas marcas, desconsidera-se a relação cognitiva, interpretativa e reflexiva que o ato leitor cria neste movimento interativo de produção de sentidos com a própria exterioridade. Deixando de lado, também, o ato criador contido na feitura do mesmo e que tem, no leitor, um pintor a tingir com sua interpretação a cada leitura da palavra concretizada em livro ${ }^{3}$.

A palavra não foi criada para submeter-se ao papel ou a qualquer outra matriz de registro, seja bidimensional, seja randômica, haja vista as narrativas orais dos "rapsodos" e "aedos", poetas compositores e intérpretes que encantavam com sua arte e tecida por fios do passado e do presente, dando-nos a conhecer sua história, seus costumes e tradições, desde a Antiguidade até nossa contemporaneidade. (LOBO, 2012).

O mais importante nessa perspectiva é que na materialidade do livro a palavra ultrapassa a bidimensionalidade do papel ao ser interpretada, mutilada, reencenada e, por vezes, ironicamente esquecida no texto pelas múltiplas leituras, que, não raro, são feitas por um mesmo leitor, em diferentes momentos de sua história, ou mesmo em distintos estados de humor.

\footnotetext{
${ }^{3}$ Cf. também Faria e Pericão (2008, p.458) que definem livro como "Conjunto de cadernos, manuscritos ou impressos, costurados ordenadamente e formando um bloco • obra, científica ou literária, que forma ou pode formar um volume - cada uma das partes principais em que se dividem os textos dos livros • documento impresso ou não-impresso • transcrição do pensamento por meio de uma técnica de escrita em qualquer suporte com quaisquer processos de inscrição. O livro supõe um suporte, signos, um processo de inscrição, um significado. Integra-se num processo de criação, reprodução, distribuição, conservação e comunicação".
} 
Neste sentido, no conceito de obra aberta, descrito por Eco (1991, p.51) a respeito da obra de arte, a noção de "abertura" nos parece propícia por compreender as várias possibilidades de interpretação que um livro consente. $\mathrm{O}$ fato de configurar-se na ideia de inacabamento, de ação de liberdade e de inventividade que repercutem em seus leitores-fruidores, o livro como espaço aberto traz uma gama de interpretações pela capacidade de mobilidade "[...] de reproduzir-se caleidoscopicamente aos olhos do fruidor como eternamente novos".

Para Eco (1991) a obra aberta pode ser compreendida em três margens de configuração: em primeira instância como obra inacabada, que convida a uma possível coautoria, no fazer a obra junto com o autor; em segunda instância como uma obra em movimento, que mesmo finalizada está aberta a percepções; e em terceira, uma obra mesmo finalizada continua aberta a uma infinidade de leituras, de múltiplas de interpretações. É esse movimento que revitaliza a obra, devido a singularidade das percepções.

Outra compreensão de livro como algo mais abrangente para além de que um simples encadernado de papeis é apresentada por Sartre (2004, p.47), afirmando que “[...] cada livro é uma recuperação da totalidade do ser; cada um deles apresenta essa totalidade do espectador. Pois é bem esta finalidade de última arte: recuperar este mundo, mostrando-o tal como ele é, mas como se tivesse origem na liberdade humana".

A palavra, organizada ou não, no sentido de uma sintaxe linear, impressa e encadernada, compõe a obra e ali inaugura um espaço de criação e de interlocução. A interatividade entre leitor e a obra decorre da ação leitora, uma relação que para Sartre (2004, p.22) parece estar envolvida de arte sedutora, inebriante e envolvente da narrativa. O filósofo considera que a palavra é transparente, pois permite ver através dela, mas “[...] num livro ela se esconde, age por persuasão como o charme de uma voz ou de um rosto; não constrange, mas predispõe sem que se perceba, e acreditamos ceder a argumentos quando, na verdade, estamos sendo solicitados por um encanto que não se vê".

Em estudos anteriores, Goulart (2009, 2011, 2014), indica que a liberdade do leitor frente ao texto apresenta certa vulnerabilidade pelo fato de o livro, enquanto objeto concreto, ser um provocador de ações e pelas práticas da comunidade leitora na qual está inserido. A história da leitura possibilita não só a percepção como o registro dessas mudanças, no decorrer do tempo, nos atos e nas razões de se ler. 
Segundo a autora, a compreensão de livro alarga-se ao percebê-lo como objeto que incita gestos, habilidades, competências, desejos, valores e significados. Há um esforço de investigação sobre a posição que ele ocupa no encontro com o leitor no momento da leitura. Focalizar o livro como aquele que não só se oferece como objeto para ser lido, nem exclusivamente como algo marcado por protocolos orientadores dos itinerários da leitura, mas como objeto carregado de valores, sentidos simbólicos dados culturalmente pelas comunidades de leitores, abrem outras perspectivas de leitura, o que Eco (1991) nos apresenta como a abertura estética da obra.

Dito de outro modo, um livro materializa, por meio da leitura, os signos que nos contextualizam histórica, social e culturalmente, graças a ação simbólica redimensionamos, atualizamos e, possivelmente, expandimos nossa visão de mundo. $\mathrm{O}$ ato de ler tem a ver com a corporeidade, pois ao lermos, estabelecemos vínculos entre passado, presente e futuro que nos conectam com sensações e sentimentos. São aromas e sons do passado, futuros imaginados e sensações outras que habitam as reminiscências de nossa memória e se esvaem pelo nosso corpo pelo ato de leitura.

Neste viés reflexivo e argumentativo, entendemos que entre o leitor e a atividade de leitura, mediados por um objeto-livro, ocorre uma multiplicidade de sentidos que transcende o espaço físico delimitado pelo texto escrito, criando agenciamentos outros de espaços que se modificam de acordo com as conexões que estabelecem. Estes lugares alhures são identificados, neste estudo, como espaço corpóreo, de experiência e de criação, não isolados entre si, mas antes vistos como espaços que se integram e se relacionam num movimento dialógico.

\section{O livro como espaço corpóreo}

Para explorar a ideia corpórea, a definição de livro proposta por Sartre (2004), parece dialogar com o conceito de $\mathrm{CsO}^{4}$ dos filósofos Deleuze e Guattari. O $\mathrm{CsO}$ do livro tem a ver com a possibilidade de conexão entre diferentes signos, que resultam na multiplicidade que eliminaria a relação dicotômica entre sujeito-objeto e entre um "eu" que daria lugar a um "nós".

\footnotetext{
4 "O $C s O$ é o campo de imanência do desejo, o plano de consistência própria do desejo (ali onde o desejo se define como processo de produção, sem referência a qualquer instância exterior, falta que virá torná-lo oco, prazer que viria preenchê-lo)". (DELEUZE E GUATTARI, 1996, p.15).
} 
Nesse sentido, o livro como corpo é o espaço a ser preenchido e esvaziado constantemente e que, consequentemente, abarca a totalidade do ser, como apontou Sartre (2004). Não se trata mais do sujeito unívoco, mas do sujeito capaz de constituir ambiências nas quais os signos podem migrar superando posturas cristalizadas.

Deleuze e Guattari (1995, p.10), descrevem o livro como o "corpo sem órgãos”, ou seja, como uma forma de agenciamento que regula uma multiplicidade indefinida de ações, gerando uma conexão com outros $\mathrm{CsOs,} \mathrm{que} \mathrm{não} \mathrm{necessariamente} \mathrm{livros.}$

A ideia de agenciamentos coletivos e de enunciação atribui ao livro uma não limitação de definição restrita à fabricação ou às marcas da exterioridade, composta de cor, forma tamanho, textura, mas de regulações que o envolve, ou seja, permite compreender que a ideia de livro vai além destes quesitos. Compreende tanto o conjunto de ações que vai desde a composição da obra pelo autor, a editoração, à disponibilização para venda, até chegar ao leitor, num "circuito de comunicação", conforme descreve Darnton (1990), quanto pelas ações de produção de sentidos que o envolve na ação leitora.

Mais ainda, o agenciamento tem a ver com os espaços que preenchemos com nossas leituras, às quais proporcionam links de acesso à nossa história, nossa cultura e outros elementos que nos constituem como leitores. Por isso, um livro não tem objeto, tem-se apenas conexões com outros agenciamentos, isto é, outros CsOs.

É esta perspectiva de agenciamento que torna o livro, segundo os filósofos Deleuze e Guattari (1995, p.10), “[...] uma espécie de organismo, ou uma totalidade significante”. A definição de livro assume, então, uma complexidade que evolve tanto a materialidade física, a exemplo da configuração e dos dispositivos gráficos e textuais, quanto aspectos não materializados como os modos, as ações e as relações que a ultrapassam, visto que

Um livro não tem objeto nem sujeito; é feito de matérias diferentemente formadas, de datas e velocidades muito diferentes. Desde que se atribui um livro a um sujeito, negligencia-se este trabalho das matérias e a exterioridade de suas correlações. Fabrica-se um bom Deus para movimentos geológicos. Num livro, como em qualquer coisa, há linhas de articulação ou segmentaridade, estratos, territorialidades, mas também linhas de fuga, movimentos de desterritorialização e desestratificação. (DELEUZE E GUATTARI, 1995, p.10) 
Para os autores o ato de escrever não se trata de um ato de pura significação, mas tem a ver com o ato de "agrimensar" de "cartografar", estudar e medir superfícies não conhecidas, que ainda estão por vir. Isso exige uma capacidade de percepção e de articulação entre o que se apresenta diante dos olhos e o que se oculta, tencionando, desta forma, os limites entre inventividade e criação imaginária. Essa percepção tem a ver com a atitude interdisciplinar adotada pelo leitor por ocasião de suas diversas leituras.

Neste contexto, para os filósofos o livro é rizoma, entendendo que

O rizoma é uma antigenealogia. É uma memória curta ou uma antimemória. O rizoma procede por variação, expansão, conquista, captura, picada. Oposto ao grafismo, ao desenho ou à fotografia, oposto aos decalques, o rizoma se refere a um mapa que deve ser produzido, construído, sempre desmontável, conectável, reversível, modificável, com múltiplas entradas e saídas, com suas linhas de fuga. São os decalques que é preciso referir aos mapas e não o inverso. (DELEUZE E GUATTARI, 1995, p.13)

O livro como um sistema rizomático traduz-se como espaço não fechado ou limitado em si mesmo; trata-se antes de um espaço aberto, um "agenciamento coletivo de enunciações" que articulam a multiplicidade em simultaneidade ao fluxo semiótico o significado -, o fluxo material - o significante - e o fluxo social, mediante o diálogo entre o autor e o leitor.

Nesse espaço aberto, a cadeia semiótica se constitui de elementos linguísticos e não linguísticos, a partir dos quais a linguagem pode ser descentrada, expandindo-se para outras formas de registro e a outras dimensões sígnicas. O que se erige, então, é a relação polifônica entre as vozes do autor, do interior da obra e da realidade mesma, na qual o sujeito leitor se insere.

\footnotetext{
Não se tem mais uma tripartição entre um campo de realidade, o mundo, um campo de representação, o livro, e um campo de subjetividade, o autor. Mas um agenciamento põe em conexão certas multiplicidades tomadas em cada uma destas ordens, de tal maneira que um livro não tem sua continuação no livro seguinte, nem seu objeto no mundo nem seu sujeito em um ou em vários autores. (DELEUZE E GUATTARI,1995, p.13)
}

No mesmo esteio das concepções de Deleuze e Guattari, Malufe (2012) aponta para a importância do livro e para noção de "agenciamento coletivo de enunciações", 
vinculando-se às coligações que envolvem tal agenciamento possibilitando, dessa forma, a interação e o diálogo com outras "máquinas" às quais o livro, também como uma "máquina" se conecta, criando outras linhas de expansão discursiva.

Para Malufe (2012, p.201), uma obra ou um enunciado encontrará seu sentido no momento em que acontecer para um leitor, seja um ouvinte ou um destinatário qualquer, mesmo porvir, como agenciamento, isto porque deve "[...] ser visto como uma peça, uma pequena engrenagem de uma máquina muito maior - com a qual, ou as quais, ele irá se compor".

Nota-se que tais agenciamentos não são estáticos, pois estão em constante variação, ao que Deleuze e Guattari (1995), chamam de "processos de “desterritorialização" e reterritorialização". É sob a perspectiva dos agenciamentos coletivos de enunciação, inclusive, que começamos a entender um poema, um livro ou mesmo toda a obra de um escritor como território, um corpo devir, como nos mostra Marques (2013).

Segundo o autor tem-se na obra literária um regime de signos (uma semântica), composta por discursos indiretos que a todo instante se atravessam, num processo interdiscursivo, dialógico, demarcando uma interação semântica “[...] como um agenciamento maquínico de corpos que são os corpos do escritor, do livro, etc." (MARQUES, 2013, p.14).

Esta interação semiótica é o movimento de intercâmbio entre diferentes agenciamentos, ou seja, uma tensão entre a tríade: autor, produção escrita - entendendo tanto o texto quanto a materialidade da obra - e leitor em busca da produção de sentidos.

O livro, suporte para abarcar um texto, seja este verbal ou não-verbal, constituise em agenciamento movido pela intencionalidade de um autor ou editor, mas não se limita a este espaço de produção textual, já que cria outros, tendo em vista a ação leitora. Não se limita ao movimento de "territorialização", no sentido de fixação e estabilidade, mas de um espaço no qual o texto, temporariamente se ancora para em seguida proceder a "desterritorialização", mediante a construção de linhas de fugas criadas pela leitura.

\footnotetext{
${ }^{5}$ Cf. Deleuze e Guattari (1995, p.12): "Um livro existe apenas no fora e pelo fora. Assim sendo, o próprio livro é uma máquina, que relação, por sua vez, mensurável, esta máquina literária entretém com uma máquina mor, revolucionária [...]. Mas a única questão, quando se escreve, é saber com que outra máquina a máquina literária pode estar ligada, e deve estar, para funcionar".
} 
Este movimento de "desterritorialização" é consonante ao que Chartier (1999, p.19) denomina de "apropriação inventiva da obra ou do texto que recebe". Pode-se ressaltar que a apropriação é uma produção de sentidos, ou seja, um movimento próprio de cada leitor em interlocução com o texto. Percorrem-se os terrenos da singularidade que cercam o sujeito, mas que estão em circularidade com outros "agenciamentos de corpos" ou "agenciamento coletivo de enunciações".

O desterritorializar tem a ver com o reterritorializar e territorializar deleuziano, posto que a leitura orienta para outros espaços de sentido os signos (verbais ou não) do livro, esse $\mathrm{CsO}$, cuja interface e migração entre ambiências decorre da movimentação corpórea da ação leitora, na medida em que tal ação se define pelos gestos, ritmos de leitura, sensações e sentimentos despertos, entre outros.

Ler, nessa perspectiva, tem a ver com o que aponta Azevedo (2009, p.52) ao dizer que " $[\ldots]$ o ato de ler abrange um sentido intersemiótico que está centrado não apenas em um jogo sequencial, como exige o código verbal, mas também em um exercício de varredura - equivalente a um scanner digital”.

Essa percepção sobre a produção de novos signos potencializada pela leitura rompe com o paradigma de uma matriz isolada e estanque, tanto no sentido espacial quanto no temporal.

\section{O livro como espaço de experiência}

Se o livro é o espaço corpóreo atuando junto a ação leitora, também corpóreo é o espaço da experiência, pois lida com as heteroglossias, ou seja, com as diversidades de linguagens e de idiossincrasias nas quais se configuram os múltiplos sentidos da leitura.

Do ponto de vista do gênero narrativo, podemos dizer que a leitura, neste caso, nos remete à nossa experiência e esta, por sua vez, decorre também de nossa capacidade de narrar e de transmitir as histórias que ouvimos. É graças a essa capacidade de narrar e de intercambiar experiências que aplacamos nossas angústias diante da efemeridade da existência.

Narrar e contar histórias tem a ver com a experiência à luz do conceito do filósofo Walter Benjamin (1994a, p.2), segundo o qual, “[...] a experiência que passa de pessoa a pessoa é a fonte a que recorreram todos os narradores. E, entre as narrativas escritas, as melhores são as que menos se distinguem das histórias orais contadas pelos inúmeros narradores anônimos". 
O livro que traz uma narrativa aproximando escrita e oralidade, conforme Benjamin (1994a) anuncia, corrobora que não há experiência mais marcante do que aquela vivida pelo próprio corpo, daí tem-se à leitura a ação de despertar nossas memórias de forma a nos enternecer, nos fazer suar, vibrar ou entristecer, entre tantas outras possibilidades.

Todavia, não se trata de criar um cenário dramático no sentido de comiseração, ao contrário, o narrador é aquele sábio, capaz de aconselhar, pois ao longo da vida amealhou experiências suas e de outrem, assim, para ele o narrar tem a ver com simplicidade, já que,

Quanto maior a naturalidade com que o narrador renuncia às sutilezas psicológicas, mais facilmente a história se gravará na memória do ouvinte, mais completamente ela se assimilará na sua própria experiência e mais irresistivelmente ele cederá à inclinação de recontála um dia. Esse processo de assimilação se dá em camadas muito profundas e exige um estado cada vez mais raro. (BENJAMIN, 1994b, p.204)

Para o filósofo (1994b, p.205) quando a humanidade já não direciona mais o olhar sobre a experiência de vida; “[...] desaparece o dom de ouvir, e desaparece a comunidade de ouvintes. Contar histórias sempre foi a arte de contá-las de novo, e ela se perde quando as histórias não são mais conservadas".

Se não é possível viver a experiência de uma narrativa como um narrador, isso gera uma situação de pobreza, isto é, "pobreza de experiência: não se deve imaginar que os homens aspirem a novas experiências. Não, eles aspiram a liberdade de toda experiência”. (BENJAMIN, 1994a, p.118)

A experiência pode ser compreendida como uma riqueza extraída da experiência humana, o patrimônio de maior valor que se pode adquirir e sua ausência, na qual está circunscrita a incapacidade de narrar leva à pobreza, como apontou Benjamin.

Ficamos pobres. Abandonamos uma depois da outra todas as peças do patrimônio humano, tivemos que empenhá-las muitas vezes a um centésimo do seu valor para recebermos em troca a moeda miúda do atual (BENJAMIN, 1994a, p.119).

Experiência e narrativa são faces da mesma moeda, a ausência da primeira implica o empobrecimento da segunda, todavia, cabe dizer que apesar de o conceito de experiência em Benjamin (1994a) ser marcado pelo contexto histórico do pós-guerra, da Revista Leitura V.2 no 56 - jul/dez 2016 - Número regular - Autor/a: Ilsa do Carmo Vieira Goulart; Dalva de Souza Lobo - p. 05-25. 
qual os homens voltavam sem ter o que contar porque tudo que traziam como experiência eram a morte e a miséria que os calava, cabe dizer que a narrativa também é da ordem do simples contar e encantar.

Como nos lembra Mário Quintana (2006, p.60) a narrativa nos encanta, nos enfeitiça:

\begin{abstract}
Mestra de estilo, feiticeira da arte narrativa, era aquela negra velha que nos contava histórias em pequeninos. Ficávamos literalmente no ar, nem respirávamos quando ela, encompridando a corda, dizia arrastadamente esta longa frase, cheia de nada e de tudo:

- E vai daí o príncipe pegou e disse...
\end{abstract}

A narrativa se encontra em meio a uma prática de contar e de ouvir de histórias. São personagens, príncipes e princesas, contos de assombração, de seres meio bicho, meio homem, de tragédias, de dificuldades, de viagens, de lutas e conquistas, ao redor de um fogão à lenha, uma fogueira ou alpendre da casa. Ela tem a ver com a reunião de pessoas que desenrolavam fios de uma narrativa, no qual entrelaçavam histórias e com isso asseguravam a atenção do público ouvinte.

Por isso, quando movidos pela ânsia de atingir a plenitude da informação ou informatização da atualidade, deixamos de lado a experiência e em decorrência disso surge um estado de mendicância. A informação traz um significado entremeado de ser/estar algo recente, novo, e tem seu ápice enquanto impera o título de atual, em contradição à narrativa, pois,

A informação só tem valor no momento em que é nova. Ela só vive nesse momento, precisa entregar-se inteiramente a ele e sem perda de tempo tem que se explicar nele. Muito diferente é a narrativa. Ela não se entrega. Ela conserva suas forças e depois de muito tempo ainda é capaz de se desenvolver. (BENJAMIN, 1994, p.204b)

Nesta direção, Larrosa (2002) procura definir experiência explorando seis aspectos que a envolvem e que estão ligados à própria palavra. Com isso, busca na etimologia do vocábulo ou nas ideias que o revestem, a presença de algo que necessita ser vivido e sentido pelo indivíduo: “[...] a experiência é em primeiro lugar um encontro ou uma relação com algo que se experimenta, que se prova. [...] o que nos acontece, ou o que nos toca”. (LARROSA, 2002, p.25)

Para este autor, a experiência não se resume a um acúmulo de saberes; ela é algo além de uma vivência, de uma situação que nos ocorre, e viver uma circunstância 
não significa para ele ter uma experiência. Pode-se viajar ou visitar um lugar, mas caso esta vivência não lhe tenha tocado interiormente, este fato não gera uma experiência.

A experiência está também relacionada a um saber, que é diferente de conhecimento. "Este é o saber da experiência: o que se adquire no modo como alguém vai respondendo ao longo da vida e no modo como vamos dando sentido ao acontecer do que nos acontece". (LARROSA, 2002, p.27)

Bem distante da detenção e posse de informação e de conhecimento que se instalou na sociedade contemporânea, na qual se destacam quantidade e atualidade, a experiência não gera estoques, ela é a própria ação de se permitir, de deixar-se seduzir pelo olhar, pelo ouvir, pelo toque, por uma aglutinação de sentidos, por uma entrega às sensações, num abolir de emoções, cuja inteireza do ser consente uma apropriação do fato vivido, um momento em que "[...] a alma, o olho e a mão estão assim inscritos no mesmo campo. Interagindo eles definem uma prática”. (BENJAMIN, 1994b, p.220)

Se considerarmos esta experiência muito mais do que a vivência de um fato, e como um deixar-se tomar, possuir por completo por um acontecimento ou situação, veremos então que o livro-objeto pode materializar uma experiência de leitura, sentida e experimentada pelo sujeito num determinado tempo e lugar. Ela é uma forma de conhecimento instalado no momento vivido pelo leitor junto com seu livro.

Segundo Cosson (2012, p.63) o que leva à leitura de um texto clássico ou de um determinado livro, por exemplo, é a "[...] experiência estética que ele proporciona” e que não se resume apenas ao aspecto de composição da narrativa, mas à experiência que esta narrativa evoca.

Esta experiência atrela-se ao processo de formação dos sujeitos, como nos mostra Larrosa (2001, p.133), trata-se de "[...] pensar leitura como algo que nos forma (ou nos de-forma e nos transforma), como algo que nos constitui ou nos põe em questão naquilo que somos".

Esses autores concordam com Benjamin (1994a) no que diz respeito à interface entre experiência e narrativa, visto que ambas se entrelaçam e quando materializadas pelo objeto-livro, remetem à existência humana.

Pesquisas com escritas de memoriais como de Cunha e Ometto (2012), revelam o quando a leitura literária impacta no processo de formação docente; ou de Petit (2010), com professores da zona rural ou desprivilegiadas economicamente, demonstram que em situações muitas vezes desajustadas da vida, a leitura se mostra o ponto culminante na formação e transformação interior. 
Na pesquisa de Goulart (2009, 2011), os depoimentos mostraram o quanto as histórias contidas nos livros e as experiências vivenciadas com estes artefatos eram, para eles, impressionantes e contagiantes. Quer pelas histórias, quer pelas atividades de leitura, realizadas pelos leitores entrevistados, o leitor age, sente e vivência situações que são compartilhadas com o objeto-livro, e nele deixam marcas de escrita ou pintura duradouras em suas páginas, ou mesmo, pela ausência de sinais, isto é, uma manipulação que excede de um selo por não macular o impresso.

Os livros trazem marcas não visíveis, marcas descobertas, apenas, quando o leitor relata as memórias de suas experiências de leitura com o objeto-livro e nelas elas percebe-se os sinais de afetividade.

Para Larrosa (2001), os livros e as obras de arte estão à disposição dos leitores de modo acessível e avolumado; consumidores de diferentes tipos de textos se põem à leitura a todo instante, mas poucos são provocadores de marcas de experiências. Tem-se o conhecimento à porta, porém nem tudo (co)move.

Assim, o livro permite um espaço em acontece na experiência da leitura, seja de fruição, seja de estudo, em que a vivência formativa supõe o ultrapassar da barreira do já sabido e do que se é, entre o que se transmite como conhecimento e o que nos passa, a capacidade de produzir sentidos e a possibilidade de uma multiplicidade intervenções pessoais, conforme descreve Eco (1991).

\section{O livro como espaço de criação}

Ler pelo não, além da letra, ver, em cada rima vera, a prima pedra, Onde a forma perdida procura seus etcéteras. Paulo Leminski (1987)

O espaço de criação que a leitura de uma obra remete é inesgotável, excede reflexões e estudos por adentrar em linhas de fugas imaginárias e dialógicas no ato de produção textual por parte do sujeito leitor.

Em relação ao letramento literário, Cosson (2012) descreve-o a partir de três etapas no processo de formação do leitor, denominados de introdução, leitura e interpretação. Mediante a complexidade das discussões sobre interpretação, o autor apresenta-a a partir de dois momentos em sua configuração: um interior e outro exterior. $\mathrm{O}$ interior relaciona-se ao processo de decifração propriamente dito, em que o leitor regula uma compreensão a partir dos signos linguísticos decodificados. Embora descrito como um ato individualizado, Cosson entende que a interpretação aciona a visão de 
mundo particular e a partir das leituras vivenciadas e experienciadas pelos sujeitos, configura-se o ato social.

O segundo momento caracterizado por Cosson (2012) como externo, refere-se a modos de materialização da interpretação, como um ato de construção de sentidos, assim, quando se finaliza uma obra, os sujeitos leitores querem compartilhá-la, desejam comentá-la, dividir com outros sujeitos a leitura vivenciada e experienciada.

Um movimento que põe em jogo a criação imaginária, em que os sujeitos leitores, a partir do texto lido, saltam em "voos imaginários", conforme Certeau (2007). Esse autor descreve a leitura como estar alhures, como o peregrinar em terras, em propriedades estrangeiras, em busca por sentidos.

Já para Larrosa (2001, p.135), na Antiguidade, a imaginação era antes a ponte de conexão "entre o sensível e o inteligível, entre a forma e o intelecto". O ato criativo está relacionado à competência produtiva da linguagem, caracteriza-se como ação e atuação do sujeito num plano verbal e não-verbal, de modo que "[...] a imaginação, assim como a linguagem, produz realidade, a incrementa e a transforma”.

Ao acionar esta linguagem imaginativa e criativa, confirma-se, assim como Quiroga (2000, p.1), que “[...] leer comprensivamente es vida”. A compreensibilidade do texto materializada em um livro, possibilita criar diferentes espaços em que é possível evadir-se, permite ações e reflexões sobre o lido e o vivido, sem controles ou manobras pré-estabelecidas, segundo Petit (2003, p.8)

[...] es como un espacio para tomar un nuevo aire, para reconstruirse, para rehacerse. Allí se perfila otra representación de sí mismo. Pero no es unicamente un escape o un lote de consolación para aquellas y aquellos que se sienten encerrados.

E este espaço criado a partir da experiência de leitura vivida pelo próprio corpo producente de sentidos em forma de linguagens, move-se por caminhos de produtividade, denominados aqui como "ação desejante".

A ação desejante figura-se a partir da ideia de "leitura desejante", defendida por Barthes (2004, p.33), como o aspecto erótico da leitura, como a ação inebriante do ato de ler, marcada por dois traços determinantes: um de entrega total do leitor ao ato de ler, mergulhando em um estado aleatório ao mundo real, o evadir-se, na criação de linhas de fuga do mundo concreto, que seriam os campos de agenciamentos, o $\mathrm{CsO}$, descritos por Deleuze e Guattari (1995). 
Diante disso, Barthes (2004) afirma que o sujeito-leitor é um sujeito apaixonado. Uma proposição retomada por Larrosa (2006b, p.64) ao descrever que por experiência leitora, não estaria relacionada à ação, ou à prática, ou a uma técnica a ser ensinada, mas antes compreende "a la pasion", isto porque "[...] la experiência es atención, escucha, apertura, disponibilidade, sensibilidade, vulnerabilidade, ex-posición”.

A ação leitora apresentada por estes autores corrobora a capacidade de introspecção do sujeito leitor e remonta a um processo singular e único entre este e o livro. Quando em posse do objeto-livro, como diria Barthes (2004, p. 37), o leitor numa atitude de isolamento, mesmo diante de outros sujeitos, ocorre um desinvestir-se do mundo exterior, uma retirada da realidade e abre-se um espaço paralelo em que "[...] o sujeito é deportado sob o registro do Imaginário". O que não significa uma ação solitária, tem-se sempre o outro "eu" e o "outro místico" como companhia, pois se trata de uma relação dialógica, de intercâmbio entre sujeitos concretizada com e pelo objetolivro, o que seria para Bakhtin $(2006,2010)$ o próprio interlocutor, numa relação interativa e responsiva da linguagem.

Para Barthes (2004), este momento de fuga não seria algo acabado em si mesmo, em função da necessidade de "ex-posición”, de expor-se diante do lido. Esta exposição, aqui delineada como a ação desejante do leitor, compreenderia as emoções imbricadas no próprio corpo durante a relação entre leitor-livro provocada pela leitura. A primeira exposição perpassa pelos sentidos, transcorre um corpo que se expressa uma linguagem não-verbal, entre a fascinação, a vagância, o contentamento, o descontentamento, a posição incômoda, a sonolência, a inquietação, entre outras.

A ação desejante compreenderia, também, o encantamento por determinadas palavras, por expressões que se destacam frente a outras, o que emerge a necessidade de exposição visual daquilo que se encantou. O leitor busca retê-las de algum modo, por isso a materialidade do livro torna-se o espaço de criação, como na nomeação, num grifo, num destaque, numa síntese da ideia, num lembrete, em anotações esparsas. A materialidade da obra torna-se um espaço para firmar marcos de atuação e interação ao texto lido.

Compreenderia, ainda, o desejo de estar adiante do enredo, de querer saber o próximo ato, a curiosidade instigante, que move o leitor a ir adiante, que provoca a inquietude, que emite emoções. O que provoca o ato desejante de estar com o objetolivro, de não o deixar vagante e solitário, a presença da obra, aguça rememorações seja do texto lido, seja da experiência de leitura vivenciada.

Revista Leitura V.2 no 56 - jul/dez 2016 - Número regular - Autor/a: Ilsa do Carmo Vieira Goulart; Dalva de Souza Lobo - p. 05-25. 
E outra ação desejante seria a arte da criação escritora. Para Barthes (2004) a leitura é uma linha condutora do desejo de escrever. A arte de criação escritora para Barthes (2004) não seria de ocupar o espaço do autor, mas do desejo de (des)escrever, reescrever, de (re)compreender ou, talvez, de escrever como o outro escreveu. O livro, como objeto que evoca imagens, provoca aspirações de produção, ou seja, na necessidade de se abrir espaços de criação.

\section{Considerações Finais}

A reflexão teórica aqui proposta apontou para as representações do que se entende por livro, o que leva, também, às questões descritas por Borges (1985, p.11) "Que são as palavras impressas em um livro? Que significam estes símbolos mortos? Nada, absolutamente. Que é um livro se não o abrimos? É, simplesmente, um cubo de papel e couro, com folhas". Mas se o lemos, acontece uma coisa rara, ocorre a desterritorialização, a abertura de espaços a cada instante pela ação leitora.

Este trabalho, guiado pela finalidade de compreender algumas proposições e discussões que abordam a temática do livro impresso, procurou apresentar algumas definições sobre o objeto-livro, aproximando concepções teóricas que dialogam entre si, de modo a construir uma ideia de livro a partir de espaços de ação, interação e atuação entre o leitor e a atividade de leitura.

Tal reflexão permite apontar que entre o leitor e a atividade de leitura mediada por um objeto-livro, ocorre uma multiplicidade de sentidos que transcende o espaço físico delimitado pelo texto escrito, ultrapassando a dimensão da materialidade, de modo que o livro se destaca como objeto de agenciamentos de espaços outros, visualizados neste texto como espaço corpóreo, de experiência e de criação, os quais e atuam em movimentos interdependentes, articulados.

O objeto-livro como provocador de espaços não limitados pelo escrito no sentido de sua linearidade linguística, e como uma ampliação cognitiva, leva a compreensão de que os movimentos de "desterritorialização", de "apropriação inventiva" da obra ou do texto lido, de ação desejante são permeados pela expressividade da linguagem. Movimentos que primam pela produção de sentidos, ou seja, pela busca desejante da interlocução com o texto.

Entre o leitor e a leitura, o livro coloca-se como espaços experiências, de singularidade, de encontro consigo mesmo, como espaço da subjetividade leitora Revista Leitura V.2 no 56 - jul/dez 2016 - Número regular - Autor/a: Ilsa do Carmo Vieira Goulart; Dalva de Souza Lobo - p. 05-25. 
entrelaçando a polaridade do texto à coletividade na criação de diálogos e interações que vão além do escrito.

Pensar no livro como espaço de relações dialógicas, remete às (in)definições, pois nas palavras de Larrosa (2006a, p.8), “[...] quizá ser uno e múltiple mediante la lectura, habitar y desabitarse a través del lenguaje; del um lenguaje que no classifica, desclassifica, desloca, des-posiciona”.

$\mathrm{O}$ ato leitor preenche ao mesmo tempo em que é preenchido pelas linhas que ora territorializam, ora desterritorializam as relações entre o leitor, a obra e a leitura. Relações que escapam ao imediatismo e à fragmentação e colocam-se também como corpos em devir, e, portanto, capazes de narrar as experiências com as quais definimos nossa humanidade e perpetuamos nosso sentido de existência.

Mais do que definir, nossa tentativa foi a de (in)definir a tríade livro, leitor e leitura, se não visamos mais provocar do que responder, ao menos porque escrever e ler na perspectiva da indefinição traduziu, nesse artigo, o prazer do texto como espaço de embates, tensões e afetos que se somam à nossa ação como leitoras de nós mesmas e do outro, sem o qual não há intercâmbio de experiências.

\section{Referências}

AZEVEDO, W. Interpoesia: o início da escritura expandida. Tese de Pós-Doutorado. Paris: Université Paris 8 - Sorbonne - Laboratoire de Paragraphe, 2009.

BAKHTIN, M. M. Marxismo e filosofia da linguagem. São Paulo: Hucitec, 2006.

Para uma filosofia do ato responsável. Tradução Valdemir Miotello e Carlos Arberto Faraco. São Carlos: Pedro \& João Editores, 2010.

BARTHES, R. O rumor da língua. Tradução Mario Laranjeira. 2. ed. São Paulo: Martins Fontes, 2004, p.462.

BENJAMIN, W. Magia e técnica. Arte e política. Obras escolhidas. 7. ed. São Paulo, Brasiliense, 1994a.

O narrador: considerações sobre a obra de Nikolai Leskov. In: Magia e técnica, arte e política: ensaios sobre literatura e história da cultura. São Paulo: Brasiliense, 1994b. p.197-221.

BORGES, J. L. Cinco visões pessoais. Tradução Maria Rosinda da Silva. Brasília: UNB, 1985.

Revista Leitura V.2 no 56 - jul/dez 2016 - Número regular - Autor/a: Ilsa do Carmo Vieira Goulart; Dalva de Souza Lobo - p. 05-25. 
CAVAlLO, G.; CHARTIER, R. (Orgs.). História da leitura no mundo ocidental. São Paulo: Ática, 1998. Vol. I e II.

CERTEAU, M. A invenção do Cotidiano. Artes de fazer. Petrópolis: Vozes, 2007.

CHARTIER, R. História Cultural: entre práticas e representações. Trad. M. M.

Galhardo. Lisboa: Difel; Rio de Janeiro: Bertrand Brasil, 1990.

A ordem dos livros: leitores, autores e bibliotecas na Europa entre os séculos XIV e XVIII. Tradução M. Del Priore. Brasília: Ed. UnB, 1994.

(Org.). Práticas da leitura. São Paulo: Estação da Liberdade, 1996.

A aventura do livro: do leitor ao navegador. Trad. Reginaldo de Moraes. São Paulo: UNESP, 1999.

A história ou a leitura do tempo. Belo Horizonte: Autêntica, 2009.

COSSON, R. Letramento literário: teoria e prática. 2. ed. São Paulo: Contexto, 2012.

CUNHA, R. C. O. B.; OMETTO, C. B. N. A leitura como experiência de formação nos memoriais de professores. Revista Caleidoscópio, São Leopoldo, vol. 10, n. 1, p. 4957, jan./abr. 2012. Disponível:

http://revistas.unisinos.br/index.php/calidoscopio/issue/view/290 . Acesso em: 20 mar. 2016.

DARNTON, R. O beijo de Lamourette: mídia, cultura e revolução. Tradução Denise Bottmann. São Paulo: Companhia das Letras, 1990.

DELEUZE, G.; GUATTARI, F. Mil platôs - capitalismo e esquizofrenia. Tradução Aurélio Guerra Neto e Célia Pinto Costa. Rio de Janeiro: Editora 34, 1995. vol. 1.

Mil platôs - capitalismo e esquizofrenia. Tradução Aurélio Guerra Neto e Célia Pinto Costa. Rio de Janeiro: Editora 34, 1996. vol. 3.

ECO, U.; CARRIÈRE, J. Não contém com o fim do livro. Rio de Janeiro: Record, 2010a.

ECO, U. Obra aberta: forma e indeterminação nas poéticas contemporâneas. 9. ed. São Paulo: Perspectiva, 1991.

FARIA, M. I.; PERICÃO, M. da G. Dicionário do livro. Da escrita ao livro eletrônico. São Paulo: EdUsp, 2008.

GNERRE, M. Linguagem, escrita e poder. 5. ed. São Paulo: Martins Fontes, 2009.

GOULART, I. do C. V. O livro: objeto de estudo e de memória de leitura. 2009. $200 f$. Dissertação (Mestrado em Educação). Programa de Pós-Graduação em Educação, Universidade Estadual de Campinas, Campinas, 2009. 
Um livro, diferentes modos de ler. Revista Leitura: Teoria e Prática,

Campinas, vol.29, n.56, p.27-35, jan./jun., 2011. Disponível em:

http://ltp.emnuvens.com.br/ltp/issue/view/5/showToc . Acesso em: 20 jul. 2011.

Entre a materialidade do livro e a interatividade do leitor: práticas de leitura.

Revista Digital de Biblioteconomia e Ciência da Informação, Campinas, vol.12, n.2, p.1-19, maio/ago. 2014. Disponível em:

http://www.sbu.unicamp.br/seer/ojs/index.php/rbci/article/view/4102/pdf 59 . Acesso em 28 ago. 2014.

LAROSSA, J. B. Pedagogia Profana: danças, piruetas e máscaras. Tradução Alberto Veiga-Neto. Belo Horizonte: Autêntica, 2000.

Notas sobre experiência e o saber de experiência. Revista Brasileira de Educação, Rio de Janeiro, n. 19, p. 20-28, 2002.

Experiencia y narración. Revista Educación y Pedagogia, Medellin, Colombia, vol.18, p.1-5, 2006a.

Sobre la experiência II. Revista Educación y Pedagogia, Medellin, Combia, vol.18, p.1-16, 2006b.

LEMINSKI, P. Distraídos venceremos. 2. ed. São Paulo: Brasiliense, 1987.

LOBO, D. de S. A questão da oralidade in Meditações sonoras em Catatau: o texto amplificado. 2012. 222 f. Tese de Doutorado. Programa de Pós-Graduação em Letras, Universidade Presbiteriana Mackenzie, São Paulo, SP, 2012.

MACHADO, A. O fim do livro? Revista Estudos Avançados, São Paulo, vol.8, n.21, p.201-214, 1994. Disponível em: http://www.scielo.br/pdf/ea/v8n21/13 . Acesso em 28: ago. 2015.

MALUFE, A. C. Aquém ou além das metáforas: a escrita poética na filosofia de Deleuze. Revista de Letras, São Paulo, v.52, n.2, p.185-204, jul./dez. 2012. Disponível em: http://seer.fclar.unesp.br/letras/issue/view/488/showToc . Acesso em 09 set. 2015.

MARQUES, A. Filosofia da linguagem em Bakhtin, Deleuze e Guattari: proposições teóricas para Geografia e Literatura. Colóquio Nacional do Núcleo de Estudos em Espaços e Representações - NEER, V, 2013, Cuiabá, MT. Anais do V Colóquio Nacional do NEER - As representações culturais no espaço: perspectivas contemporâneas em Geografia. Cuiabá, UFMT, 2013. Disponível em: http://www.geografia.ufmt.br/neer/ANAIS/dif/Eixo\%2001\%20pdf/EIXO\%201\%20AR TIGO\%2010\%20-\%20Marcos\%20A\%20Marques.pdf . Acesso em: 09 set. 2015.

PESSOA, F. Cancioneiro. Ciberfil Literatura Digital, 2002. Disponível em: http://www3.universia.com.br/conteudo/literatura/Cancioneiro de fernando pessoa.pdf Acesso em: 06 set. 2015.

PETIT, M. A arte de ler: ou como resistir à adversidade. São Paulo: Editora 34, 2010. 
QUEIRÓS, B. C. de; ABREU, J. (Org.). Sobre ler, escrever e outros diálogos. Belo Horizonte: Autêntica, 2012.

QUIROGA, N. H. Reflexiones para abril el debate... Lectura comprensiva y vida. Revista Lectura y vida, Buenos Aires, año 21, n. 1, p.1-8, 2000.

RIBEIRO, A. E. O que é e o que não é um livro: suportes, gêneros e processos editoriais. SIMPÓSIO INTERNACIONAL DE ESTUDOS DOS GÊNEROS TEXTUAIS, IV, 2011, Natal, RN. Anais do IV Simpósio Internacional de Estudos dos gêneros textuais. Natal, UFRN, 2011. Disponível em: http://www.cchla.ufrn.br/visiget/ Acesso em: 28 ago. 2015.

SARTRE, J. O que é literatura? Tradução Carlos Felipe Moisés. São Paulo: Editora Ática, 2004.

VEIGA-NETO, A. Literatura, experiência e formação (entrevista com Jorge Larrosa). In: COSTA, M. V. (Org.). Caminhos investigativos: novos olhares na pesquisa em educação. Porto Alegre, Mediação, 1996. p. 133-161. 